\title{
Cultural constants and implicit generalized cultural script: on the relationship of cultural and psychological one
}

\begin{abstract}
In the article we discuss the relationship of cultural and psychological one. In the first half of the XX century at the beginning of the science on psychological anthropology the scientists sought to explore the culture and the psychology in the synthesis. The searches of intercultural integrator were based on this synthesis. But the psychological structure, which would integrate the culture and would be specific to it, was not detected. Since the sixties of XX century until almost its end the scientists began to study the culture in anthropology, abstracting from the psychology. Now newly attempts are being made to explore the culture in the synthesis with psychology. In the article are proposed one of the solutions to the problem. This is the concept of implicit generalized cultural script. Implicit generalized cultural script includes the ideas about the character of human action and is a psychological complex, differing from culture to culture. It predetermines what objects of the external world becomes in the human mind the meaningful systems and then forms in the culture the intentional worlds and intentional personalities.
\end{abstract}

Keywords: cultural scripts, socio-cultural system, cognitive artifacts, sets, action models, intentional world, intentional personality
Volume 3 Issue 3 - 2018

\author{
Lourié Svetlana Vladimirovna \\ Departmenet of Culturology, Sociological Institute of the \\ Russian Academy of the Sciences, Russia
}

\begin{abstract}
Correspondence: Lourié Svetlana Vladimirovna, Departmenet of Culturology, Sociological Institute of the Russian Academy of the Sciences, Russia, Email svlourie@gmail.com
\end{abstract}

Received: October 09, 2017 | Published: May 15, 2018

\section{Introduction}

So, from the point of psychological anthropology view the culture is a system of mental meanings. It encompasses all aspects of world's construct, both material and ideal, including psychic ones, if they lie within the framework accepted by culture. The culture is such structure in which all components are strongly interrelated and interdependent. What are the principles underlie this structure? That is the question. It is obvious that the cultures are little or much different from each other. Then there are principles, and common and their own unique. Let us begin with the question of how external world realities turn into intrapsychical cultural realities, or, "meaning systems", according to the terminology introduced by American cognitive anthropologist Roy D'Andrade. ${ }^{1}$ We shall also use the "material flow" term D'Andrade ${ }^{1}$ defined as follows: "There is a major class of human phenomena that is not organized as meaning systems, which I term material flow. By material flow I mean the movement of goods, services, messages, people, genes, diseases, and other potentially countable entities in space and time". ${ }^{1}$ As we suppose (perhaps, operating the term somewhat wider than D'Andrade ${ }^{1}$ did himself), "material flow" may include any other phenomena that did not become artefacts for these or those reasons, and, therefore, are not fully perceived by people in the culture, as they are not meaningfully represented.

To be perceived by people, phenomena need to become artefacts or "meaning systems": mental artefact complexes that are included into culture understood as a "field of action". Very tentatively, we shall interpret the notion of culture on the basis of the definition formulated by German cultural psychologist Ernst Boesch. According to him, "Culture is a field of action, whose contents range from objects made and used by human beings to institutions, ideas and myths. Being an action field, culture offers possibilities of, but by the same token stipulates conditions for, action; it circumscribes goals, which can be reached by certain means, but establishes limits, too, the correct or deviant actions. The relationship between the different material as well as ideational contents of the cultural field of action is a systemic one; i.e., transformations in one part of the system can have an impact on any other part". ${ }^{2}$ In order to become a component of a "cultural field of action", a "material flow" element has to go through some mental operations. In this process some components of the "material flow" will inevitably remain beyond the human perception as lying outside the "intentional world" of a human being.

Here is what cultural psychologist Richard Shweder writes of intentional worlds: "Intentional things are causally active, but only by virtue of our mental representations of them. Intentional things have no "natural" reality or identity separate from human understandings and activities. Intentional worlds do not exist independently of the intentional states (beliefs, desires and emotions) directed at them and by them, by the persons who live in them". ${ }^{3}$ Moreover Shweder says: "Intentional worlds are human artefactual worlds populated with products of our own design. A socio-cultural environment is an intentional world. It is an intentional world because its existence is real, factual, and forceful, but only as long as there exists a community of persons whose beliefs, desires, emotions, purposes and other mental representations are directed at it, and are thereby influenced by it". ${ }^{3}$ Therefore Shweder, besides the "intentional world" notion, introduces the notion of an "intentional person": "Intentional persons and intentional worlds are interdependent things that get dialectically constituted and reconstituted through the intentional activities and practices that are their products. ${ }^{3}$

So, how do external world realities become intrapsychic cultural realities? A part of "material flow" elements go through it automatically 
in the process of transmission. Progressively, as a child socializes, he adopts certain "event cultural scripts", and as he adopts these cultural scripts, he also digests its components, from separate artefacts and artefact complexes to cultural schemes or models of behaviour. In other words, a child perceives whole cultural schemes deployed in time. As children get involved into the "interpsychic" (interpersonal) interaction with other people, this interaction gradually becomes "intrapsychic" (internal, psychologically adopted) or "interiorized". ${ }^{4}$ According to Katherine Nelson, socializing their children, adults do more about directing their actions and setting their goals than about teaching them directly, immediately. Adults use their cultural scripts' knowledge to set some limits to thus, the children action, thereby allowing children get involved into the role behaviour they are expected to show, i.e. act in accordance with a definite cultural script. This way the adoption of such scripts plays the central role in culture adoption. ${ }^{5}$ At the same time, the whole cultural context determines the selection and implementation of the adopted scripts. Adopting such cultural scripts, the child also adopts artefacts around him, appropriate models of interaction and ideational contents of the cultural field of action, and the "intentional world" itself where he is going to live. ${ }^{6}$ And the children themselves become cultural objects, artefacts, as they enter the world.

Another part of "material flow" elements is adopted by means of some constant perception complexes belonging to a certain culture (we shall talk about it later), that correct the process of human perception bringing it into a culture-determined framework. By means of these constant complexes, an object or a phenomenon gets represented in the human mind, i.e. becomes an artefact. Here we may, to some extent, agree with the statement by psychological anthropologist Theodore Schwartz that culture consists of derivatives of experience, more or less organized. ${ }^{7}$ Let us summarize everything said above and formulate some key suggestions to be discussed further. First of all, we assume that constant perception complexes themselves can be regarded as artefacts. Being specific psychic processes that regulate the socio-cultural activities of a person, they are also a product of cultural activities of people and, therefore, may be presented as culture-determined and unconscious elements of human psyche. Secondly, if a person "learns" a certain way of perception through his participation in a culture, or, to be more precise, in various scripts it provides, perception and activity should be regarded as two tightly intertwined processes. Therefore, we may draw a preliminary conclusion and suggest that structure-forming elements of a culture are the perception paradigms that determine the character of human activity in the world. Thirdly, the paradigms that determine the structure and, partially, the contents of a culture itself, as a rule, remain non-realized, as otherwise a person would have been able to construct a culture and convenient cultural scripts at his own choice relatively easily. And, fourthly, these paradigms are immediately correlated with the artefacts of culture and sets of the person to them. Let us begin the analysis of the above statements from the latter, i.e. from the notions of artefacts and sets.

The notion of "artefacts" is quite diverse today. It leads to the natural tendency of building an artefact hierarchy. The most widely spread hierarchy is the one suggested by Marx Wartofsky which goes as follows:

a. Primary artefacts: material and ideal artefacts (objects or phenomena, as well as our representations of them) b. Secondary artefacts: representations of models of actions with primary artefacts

c. tertiary artefacts: the "free game" (operation of artefacts with no relation to the external world, its tendencies or any associated necessities). ${ }^{8}$

Using a similar scheme, Michael Cole adds "cognitive artefacts" into his hierarchy. ${ }^{9}$ The concept of "cognitive artefact" was initially suggested by Donald Norman whose objective was to reveal how and when the cognition of physical artefacts is formed in the human mind. ${ }^{10}$ For Norman, thinking is an autonomous kind of human activity, and artefacts are something external for human thinking. They influence, but do not construct it; they cannot be active inside human psyche. However, the most important point for Cole is that an artefact acts within the cognitive system, and cognition is a process that occurs in an individual's head. According to Cole $^{9}$ cognitive artefacts set up some information processing mechanisms. ${ }^{9}$ Cole's ${ }^{9}$ expansion of the notion brings its advantages. It gives us an opportunity to define not only the objects and phenomena, external for a human mind as artefacts, but also classify the intra-psychical ones as artefacts if they have been developed as a result of some cultural processes. Cole ${ }^{9}$ speaks of the "creatures whose minds are made through artefacts" and claims that "articles are, in some respects, models. Their structures carry within them, so to speak, a "theory" of both the human who is using them and the range of environmental circumstances in which they will be normatively used as a synthesized ensemble that satisfies the constraints of the human user and the task at hand". Cole ${ }^{9}$ believes that "at the same time artefacts are transformers, enabling the metamorphoses of what we refer to as external into internal and vice versa" and supposes that "because they enter intimately into human goal directed action, there is a functional aspect to all artefact-mediated action. And for the same reasons artefacts embody values (ought to, should, and musts); in this sense all culturally mediated action is, at least implicitly, moral action". ${ }^{9}$ Cole does not speak directly of the motivational components of artefacts, but for him artefacts are, on one hand, procedural constructs, and on the other, value constructs, and therefore, as such, they cannot but perform the motivation function.

Concerning the latter aspect, a researcher similar to Cole is Herbert Simon, for whom artefacts always remain a product of human activity, i.e. they are "synthesized by human beings". ${ }^{11}$ Moreover, it is relevant for us that Simon also speaks of such components of artefacts as goals, (as the motivation component of artefacts cannot just be left out in everything that concerns goals), functions (the process component is evident) and acts of adaptations (including the psychological ones connected with the "intentional worlds"). The resulting hierarchy of values is the following:

\section{Material artefacts}

2. Ideal artefacts (let us define them as miscellaneous, as all of them are not the same)

3. Cognitive artefacts, representations or schemes of an object in the consciousness or sub-consciousness of a person,

4. Models of actions with artefacts (including scripts), as well as

5. Goals (after Simon) and values (after Cole), adding

6. Intentional worlds (after Shweder) that are also artefacts that can be compared to tertiary artefacts of M Wartofsky. 
After D'Andrade, ${ }^{12}$ 1: are related to the category of symbols, ${ }^{12}$ 2 : to meaning systems, $3,4,5$ : to schemes of various types. So, we can see that cognitive anthropologists and cultural psychologists speak of artefacts as of mental phenomena. We shall follow them, but we shall try to deepen this approach. To do this, let us turn to the concept of a "set" just as we promised before. American cultural psychologists are mostly thrilled about the artefact theory by Soviet psychologist LS Vygotsky and particularly about his famous triangle of "subject-mediating tool-object". ${ }^{9}$ Even though, according to Vygotsky, artefacts do not lie in such evidently mental sphere as they are in the vision of American cultural psychologists, in Soviet science Vygotsky's theory had a sort of its mirror and mental reflection in the works by DN Uznadze, less known internationally. He suggested his own triangle of a "stimulus-set (unconscious readiness, willingness) for action-reaction", which can be easily transformed into "subjectset-object". Remaining within cultural psychology tradition to classify mental complexes as artefacts, we see that the "set" mentioned by Uznadze may be also qualified as an artefact. Comparing the triangles of Vygotsky and Uznadze (no one is known to have done it before), we get the following result: Generally, the scheme can be presented as: According to Uznadze, a set determines "a subject as a whole, which enters into a relation with the reality, therefore getting forced to turn to some psychic processes for help. Indeed, the subject itself in this case is primary, while its activity is something derivate". ${ }^{13}$ And as according to Uznadze, a set is subconscious and is a modus of a whole personality, connected to a category of activity expressed through the readiness for some action, it is possible, with a proviso, also speak of an acting human personality as of an artefact (Figure 1).

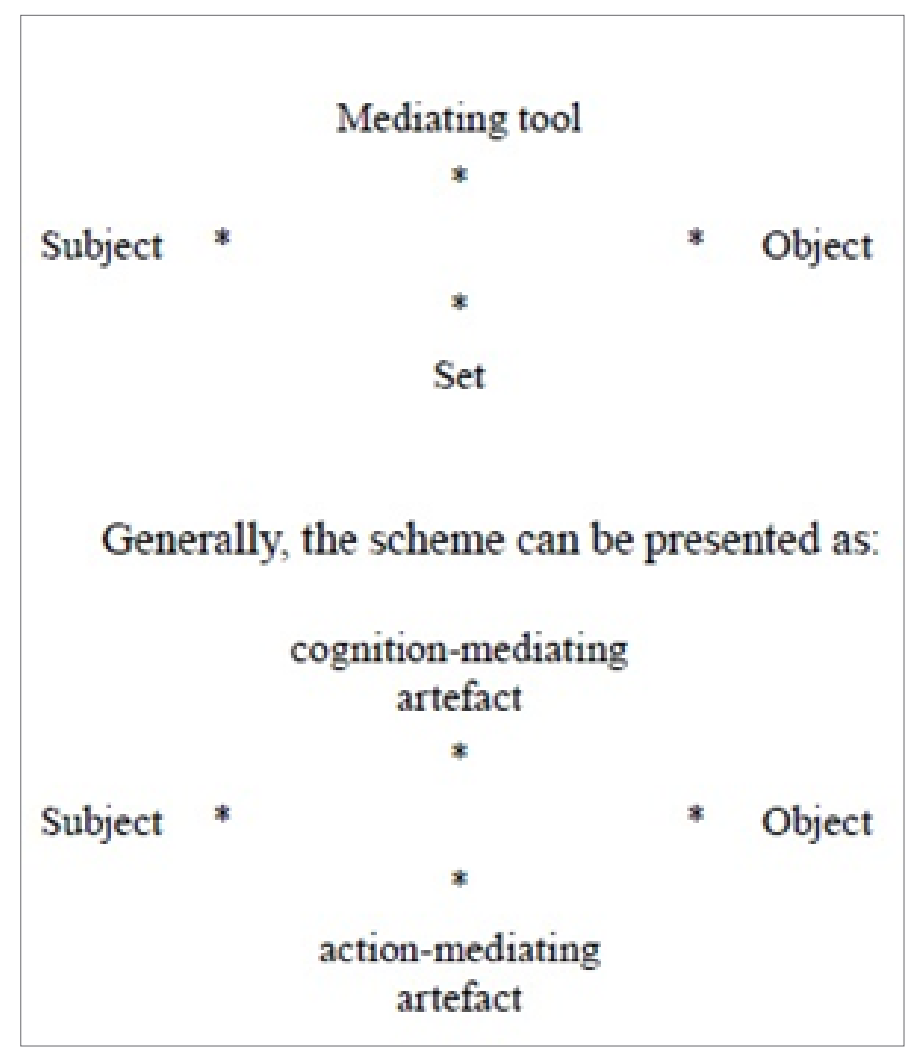

Figure I Schematic presentation of American cultural psychology.
The last statement matches cultural psychology perfectly; one of its representatives, Richard Shweder, introduced the concept of "intentional personalities" equally with the concept of "intentional worlds". If "intentional worlds" (our socio-cultural medium is also one of them), after Shweder, are artefact worlds, then "intentional personalities", correspondingly, are artefact personalities, or, in other words, personalities producing material and ideal artefacts, running the cognition process through cognitive artefacts and performing actions with the sets of their personalities, withdrawing new "meaning systems" from the "material flow". Cognitive artefacts, "meaning systems" and sets as artefacts are tightly intertwined. As stated by Uznadze's ${ }^{13}$ follower, ShA Nadirashvili, with the occurrence of a set to act in a certain direction, a person "influenced by it, notices and considers only those objects and phenomena that are connected to the set in this or that way. Neutral objects and phenomena, irrelevant for such set, remain unnoticed. The statement has been proven by a number of experimental results. Only those thoughts and contents of consciousness pop up in the person's memory, that are related to the current set in this or that way. Matching this to the concept of "meaning systems" and "material flow" by Roy D'Andrade, ${ }^{12}$ we see that we speak of the same thing. But essentially Nadirashvili also speaks of the way how "flow material" elements become "meaning systems" through the mediation of perception complexes born by sets. The function of a set is to select objects, contents of consciousness, general experience and knowledge from the surrounding medium and the person's previous experience that are necessary for the desired behaviour". ${ }^{14}$ It means that it is only action that is determined by the a; at the same time, it is also perception, and interpretation. Action and perception act as an inseparable integrity, determined by one common set, which, in its turn, is determined by what Uznadze referred to as "modus of personality".

Therefore, being an artefact which can be regarded both as (3cognitive artefact) and as (4-model of action) within the hierarchy shown above, a set is related to the integrated cultural field (to 6-"intentional world" and "intentional personality"). A set is mediated by the connection between personality and cultural field. And as, according to Uznadze, a set may be fixed, i.e. stable, continuous, we may also say that a determining culture, a set underlies various cultural representations. So, subconscious sets (consciousness is not involved at all!) "filter" the "material flow", promoting something into "meaning systems", and returning some former "meaning systems" into "material flow". This way they determine the perception of both external world and our inner experience. Therefore, sets work as tools for representing an artefact and our consciousness as an artefact in the process of action, and determining the direction of such action. As we are speaking of processes that occur within the framework of culture, we may mention not only exclusively psychological, but also some cultural and psychological complexes involved in the representation process, uniting in themselves the "meaning systems", models of actions and sets, that in totality constitute cognitive artefacts (or perception complexes).

In the context of everything said above let us look at cognitive artefacts as at perception complexes. Being specific psychic processes, regulated (besides conscious regulation, it can be done unconsciously, through sets) by sociocultural activity of a person (consisting of cultural models of action, a part of which are unconscious, i.e. based on the existing sets), perception complexes themselves are a product 
of cultural activity of a person. Moreover, in cognitive artefacts even the procedural components of perception themselves (not only their result) implicitly contain and assume the presence of certain action models. Indeed, in a way they can be taken as a special case of cognitive artefacts, but it is relevant for us to outline the perceptiveactivities artefacts. It means that we may speak of the perceptiveactivities artefacts that integrate models of action with models of perception. This is what we call "cultural constants", one of the key terms of our own concept of culture we are now approaching. But let us return to "meaning systems". They may both appear in the process of activity by themselves (extracted from "material flow"), and provoke such activity (actualizing the cognition connected to the "meaning system"). It does not only happen through its motivation function that joins culture with psychology, as mentioned by D'Andrade ${ }^{12}$ and some other psychological anthropologists, such as Milford Spiro ${ }^{15}$ or Robert LeVine, ${ }^{15}$ but also through a set, an underlying intention of human personality, developed (at least partially) and acting within a cultural framework, i.e. through transforming motivation into an instinctive necessity to do something in a certain way (with an appropriate cultural pattern). As claimed by Nadirashvili, this necessity may be fixed: "Such attitude to things can be situational, momentary, but it may get fixed and become chronic... In the process of set fixing some laws have been found that aid the formation of a certain personality type". ${ }^{14}$ An inclination to "synthesizing" these or those "meaning systems" becomes fixed. A way of perceiving reality in the way determined by one's culture also becomes fixed. So does motivation for some certain activity. Such fixed cognitive-perceptivemotivation-pattern complexes are what we call "cultural constants", where we easily find the interconnection between cognitive artefacts and set-artefacts that have been developed in the process of human activity and, particularly, in the process of interaction between individuals actualizing various cultural scripts.

A complex of cultural constants is a schematic prism through which a person looks at the world where he must act. It creates basic paradigms that determine possibility and conditions for human activity in the world, and it is around cultural constants that the whole structure of being is built in the human consciousness. It is due to cultural constants, that a person obtains such "image of the surrounding medium" where all elements of the universe are structured and related with the person himself, and only within which a person may act. That means that only thanks to cultural constants "intentional personality" and "intentional world" are formed. Just like "a set creates a psychological base for adopting a person to the surrounding medium and for transforming it according to his needs", ${ }^{14}$ cultural constants establish the target and the method of the subconscious culture-determined adaptation of the world to the personal needs, as well as the adaptation of the person to the world. A cultural constant complex includes such dynamic paradigms that reflect perception and set for action determined by this perception at the same time. At first glance, they may be operationally defined as some sorts of "images": images of a source of good and a source of evil, a protecting and an opposing power, a we-image (an image of a group of people able to act), image of a field of action, condition of action, source of action, method of action and other possible images associated action of a person in the world. Besides the properties of such images, their disposition, ways of interconnection and interaction between them are of paramount relevant. Thus, a cultural constant complex happens to be a system of images that describes the arena of action of a person as a member of the group that is the primary "we" for him (let us remind the reader that Shweder speaks of a so-called "intentional action". ${ }^{3}$ And if so, there appears a base for the reaction of "external" (intentional) conflicts in a "dramatized" way, through the interaction of images, specific and peculiar for every culture (we do not yet speak of the internal conflicts determined through the acceptance of being as intentional reality by a person as an "intentional personality"; we only speak of the conflicts within the framework of the intentional world itself). Every image has its own "character" and certain relations with other images. Through them, every culture obtains a "canon of reality perception", which is a complex of cultural representations. From this point of view, human activity is presented as an interaction of images, within which a person develops his behaviour, as though becoming one of the components of this perpetually moving system. And in this very context, which, actually, is culture, his fixed sets are developed.

Let us explain the functioning of cultural constants on a relatively simple example. Let's say, that according to the rules of some story genre, some characters are supposed to be there: a villain, a knight, a lady etc. In each and every story these characters have names and individual features, but some common properties and models of relationships between them, dynamics of the plot required by the story genre remain the same. Generally, culture creates a similar canon for universe perception. It establishes such paradigms of perception that all objects or features of the external world are either matched to the "images" developed by culture, subject to more or less significant distortions, or are not at all perceived by a person within the given culture. As environment of a socio-cultural system changes, the cultural, political, economic conditions the people lives in also change. It means, that the experience the people is expected to perceive and its structure also changes. It is like a new play written under the same canon, but based on a new plot. The "pictures of the world" will change, but thanks to "cultural constants" their underlying structure will remain the same. One "intentional world" will replace another, but their fundament will still remain the same, based on the same "cultural constants" in the same dispositions; the "skeleton" of culture will remain, but the "meat" on the "skeleton" will be different.

"The New Guinea tribes-man whose inkblot responses were our starting point may in a decade have gone from his tribe's traditional model of the cosmos through a series of radical shifts. A Fundamental missionary may have persuaded him that in the Book of Genesis and what follows lies the source of the white man's power. Within five more years he is voting for a representative in the House of Assembly, is co-owner of a truck, and has heard about men's landing on a moon he perceived as a totemic deity ten years back. It is a mystery how a man can cope with such chaotic shifts of consciousness and remain same?" asked (maybe the basic question of anthropology) anthropologists $\mathrm{R}$ and $\mathrm{F}$ Keesings. ${ }^{16}$ Maybe the reason why the man remains sane is that such shifts may be not chaotic at all. Their main concern is the things the things that are not related to the frame of the current culture. The "skeleton" of the "New Guinea tribes-man" remained the same; the only components that changed were those, the mobility of which was allowed by his culture. And it makes no difference if for an external observer the changes seem global: every culture has its logic. "Cultural constants" are not the contents of "images"; they are general "formal", "technical" characteristics ascribed to them, which finally determine the order of manifestation and perception of all the images involved in the plot. Certain filling of the paradigms may vary, and that is when new modifications and "images of the world", as well as all other images, occur. But in any case their filling will maintain the general attribute of all the images, their disposition, vision of the 
action modus the same and unchanged. These are the constants the cultural tradition in different modifications is crystallized around.

"Cultural constants" havn't being recognize by a culture representative. They are tools for structuring and "rationalization" of the experience obtained from the external world. Though the "world view" formed in people's consciousness on the basis of cultural constants may be criticized, cultural constants themselves are not subject to the people's judgments at least because people do not see or aware of them. This is where the protective mechanisms of the human psyche play their part. Thanks to them, cultural constants never reveal their contents immediately in the consciousness of their bearers; they pop up only as ideas of some certain problems or objects, i.e. in the maximally specific shape. Going through the protective barrier of human psyche, cultural constants are, in a way, fractionized: they enter the consciousness zone not as a universal rule, common for a number of various phenomena, but as a vision of the most convenient action for the specific moment. Moreover, the ways of manifestation of cultural constants may be so diverse and multiple that sometimes it is really difficult to find a common tendency underneath. The diversity of the ways for cultural constants to reveal themselves provides their "invisibility" and "invincibility". In the event of an evident contradiction in the manifestation of cultural constants or a critical mismatch of the constants with the reality, it is not the cultural constant that is threatened, but a certain form of its manifestation. Some behaviour pattern may be rejected by an individual or a community as inconsistent, but the subconscious basis of this pattern will remain unchanged and find, in this way or another, its manifestation in some other forms. Therefore, in the periods of modification of the cultural consciousness, cultural constants just change their "costumes".

The filling of cultural constants with some certain contents is a way of joining subconscious images with real phenomena (but not always within a specific tradition), or, speaking in psychoanalytic terms, is a transfer, or transposition of a unconscious complex to a real object. Such joining may be more or less stable and remain as long as an object can bear such a load within the culture-determined "picture of the world" and culture-determined experience of people, until it does not diverge from reality too much. Then another transfer occurs, but it is a transfer to a different object already. It is the intentional world transformation law. This is how, for example, the development or replacement of the "image of the protector" and "image of an enemy" (personified or not) occur. Another similar phenomenon is what we may refer to as auto transfer: a person ascribes some properties typical of the unconscious "self-image", "we-image" (concept of "we" and concept of "I") to himself. Therefore, a person is creating himself as an intentional personality, inscribing himself into the intentional community and the intentional world. The structure of relationship between unconscious images is transferred onto real experience, determining the ways of people's actions (intentional action). People act in compliance with the properties they transfer onto themselves, within the framework of the vision of the community, its properties and relations lying in their unconscious. Therefore, "material flow" is used to extract some new elements that previously remained unnoticed an ignored; they become "meaning systems", while others that formerly constituted the "meaning systems" will either retain their status as history and archaeology, or be thrown away, flushed back into "material flow".

The object the transfer is made on becomes the key of the current version of the cultural tradition. All meaning connections of the "world view" are concentrated around such "meaning objects"; they also set the plot in the life of society (socio-cultural system), as they act as mediators for projecting the conflict between the "image of the source of good" and the "image of the source of evil" the culture assumes or allows, onto actual reality. As new "meaning systems" become such and are then adopted, interiorized by a person dynamically, i.e. as a culture-determined script unfolds, we may suppose that cultural constants underlie the scripts admitted by the current culture as desired or acceptable, and, moreover, they serve as a base for building such scripts. In order to build such dynamic constructs as cultural scripts on the basis of cultural constants, it is necessary for the cultural constants themselves, acting as culture-determined mental images forming the basis for the culture as it is refracted in the psyche of its carrier, to be involved in dynamic interaction with each other. Culture is a "field of action", as defined by Ernst Boesch (as we have mentioned above) not only because all of its elements interact with each other, but also because the frame the Whole culture is built on is dynamic in its core. This is the only fact we may use to explain how changes in one elements of the cultural system may lead to changes in its other elements without breaking the culture as a whole.

It is easier to understand as follows: cultural constants contain some models of actions that are the sets for some certain activity and the idea of the way of activity, the totality of which constitutes a prototype of a script that finds its reflection in any script brought to life. In culture, any set provokes a counter set, thereby creating a frame of sets, on which "meaning systems" are "woven" and fixed, turning from "material flow" components into artefacts. It happens in the process of actualization of various specific cultural event scripts. New sets do not appear spontaneously; their target and intention is determined by culture as a whole. The frame for matching all possible specific scripts to be actualized in this or that culture is an idea of interactions underlying the culture, or, to be more precise, an idea of a principally possible structure of interactions acceptable in the given culture (considering all alternatives accepted by the culture). This idea is projected on every bearer of the given culture as an individual, acting within the culture. Intentionality let it be general universal ("intentional world") or an individual ("intentional personality") one, reflects the idea of an action, an action of an "intentional personality" in the "intentional world". Actions, activity of a personality in the world are the contents of the "intentionality" category not as much in the aspect of its objects, but in the aspect of its formal characteristics, and, therefore, of its models. The models are united into integrities of models, which are scripts, and scripts are generalized into the basic structure of a culture that we may refer to as implicit (unconscious) generalized cultural script. Though it is not the "intentional world" itself yet, it is the frame, its "intentional scheme".

Being an intentional scheme, generalized cultural script is specific for every culture; it lies beyond culture and bears a conflict in itself. Its extra logic nature is partially explained by its function to psychologically adapt the external reality, to make it more comfortable for people even if by distorting its perception (i.e. a generalized cultural script itself turns a person into an intentional personality within his culture) and a peculiar "rationalization", for example, by psychological localization of all the evil of the world in one source, so that it does not seem to be spread all around the world. Being extra logical, or, to be more precise, intentionally logical, intentionally rationally perceivable, reality inevitably becomes fundamentally contradictory in the human consciousness, evoking certain sets for action to smoothen the contradictions. That is what motivate a person into action, i.e. 
directs him to actualize the old cultural scripts or to "spontaneously synthesize" some new ones on the basis of an existing script frame. Therefore, being intentionally perceived, objective reality becomes a projection of a generalized cultural script. That is how a cognitive artefact gains its motivation power, forcing a person to act in order to minimize the perceived contradictions, stimulates development of a set as an unconscious need for an appropriate cognition of activity.

Adoption of a culture by a child, or enculturation, means adoption of the script "intentionality". Transmission of culture from one generation to another is carried out as a human being digests a huge amount of cultural event scripts and has the main principles of interaction, typical for the given culture, condensed in his consciousness and, what is especially important, in the unconscious. That is how a person unconsciously adopts, unconsciously generalizes cultural properties, cultural models determining the interaction patterns, and thereby perceives the implicit generalized cultural script specific for his culture. It should be noted that interaction principles can be common on different levels and in various aspects. The implicit generalized cultural script may be correlated to the cultural constants complex, i.e. with the general scheme of perception-interaction in the world typical of the given culture. The cultural constants complex includes the generalized notion of the "right", "correct", and, partially, "due" interaction (unlike the generalized cultural script that creates the whole spectrum of interactions possible in the given culture). A generalized cultural script and cultural constants complex are two sides of the same medal, and both of them may be presented, on one hand, as a prism the culture bearer is looking at the world, and on another hand, as a totality of culture-determined models of action.

Cultural constants complex is a perceptive-activity scheme, and generalized cultural script is a projection of this scheme on the "intentional personalities" acting in the "intentional world". Cultural constants complex may be to some extent defined as an idealized vision of the condition of the world making this or that action convenient, adapted to the human being, while implicit generalized cultural script is principally implicit. Moreover, if cultural constants may be sometimes decomposed into several elements, it is very complicated to do with a generalized cultural script. If cultural constants provide a sort of schematization of the generalized cultural script, its modal basis, then a generalized cultural script, being wider than this projection-scheme it includes all variations of actualizing cultural constants, acceptable and possible in the given culture. A generalized cultural script is a sophisticated cultural complex which includes clusters for all possibilities of perception and action represented in the given culture. A generalized cultural script is a skeleton of culture with a spine consisting of modal possibilities, modal structures of perception and action and branches of all the opportunities thinkable in the current culture, potentially including all variants of actions acceptable by the culture. ${ }^{17-20}$

\section{Conclusion}

We see the concept of an implicit generalized cultural script at the center of the science of culture, which is designed to explain the functioning of society as a socio-cultural system. The task is also to combine this system determined by culture, mental and social, with the notion of the human will, without which a person becomes only a derivative of cultural circumstances. We believe that freedom refers to the goal-setting sphere, whereas the models of action are culturally- determined and value-neutral. Freedom is a property of a person, and presents are an attribute of a socio-cultural system. The socio-cultural system serves as an intercultural integrator; it defines an implicit generalized cultural script that contains the intentionality determinate by the culture. This is such "cultural distortion" that "refines" the external world, makes it psychologically more "refine" and suitable for living in it, that is, it performs the functions of psychological adaptation. $^{21-26}$

\section{Acknowledgements}

None.

\section{Conflict of interest}

Author declares that there is no conflict of interest.

\section{References}

1. Andrade DR. Cognitive Anthropology. In: Schwartz Th, White G, Lutz C, editors. New direction in Psychological Anthropology. Cambridge: Cambridge University Press; 1994.

2. Boesch E. Symbolic Action Theory and Cultural Psychology. Berlin: Springel-Verlag; 1991.

3. Shweder R. Thinking through Cultures. Cambridge: London (England), Harvard University Press; 1991.

4. Miller J. Theory of Developmental Psychology. NY: Freeman; 1993.

5. Nelson K. Cognition in a Script Frammework. In: Flavell J, Ross L, editors. Social Cognitive Development. Cambridge: Cambridge University Press; 1981.

6. Cole M. Cultural and historical psychology. Moscow: Kogito-centr; 1996.

7. Schwartz Th. Anthropology and Psychology. In: Schwartz Th, White G, Lutz C, editors. New direction in Psychological Anthropology. Cambridge: Cambridge University Press; 1994.

8. Wartofsky M. Models Representation and the Scientific Understanding. Dordrecht: Holland/Boston: USA/L: England: D Reidel Publishing Company; 1979.

9. Cole M. Cultural mechanisms of development. Voprosy psikhologii. $1995 ; 3$.

10. Norman D. Explorations in cognition. San Francisco: Freeman; 1975.

11. Simon H. Sciences of the artificial. Cambridge: MIT Press; 1981.

12. Andrade DR. Shemas and Motivation. In: Andrade DR, Strauss C, editors. Human Motive and Culture Models. Cambridge: Cambridge University Press; 1994.

13. Uznadze D. Experimental basis of psychological set. Tbilisi: Izdatel'stvo AN GrSSR; 1961

14. Nadirashvili S. Propaganda psychology. Tbilisi: Mecniereba; 1978.

15. Spiro M. Some reflections on Cultural determinism and relativism with Special Reference to Emotion and Reason. In: Shweder R, LeVine R, editors. Cultural Theory. Essays on Mind, Self and Emotion. Cambridge L, NY, New Rochelle, Melbourne, Sydney: Cambridge University Press; 1984

16. Keesing P, Keesing F. New Perspectivers in Cultural Anthropology. New York: Holt, Rinehart and Winston; 1971.

17. Benedict R. Patterns of Culture. Boston and New York: Houghton Mifflin Company; 1934. 
18. Cole M. Culture and Cognitive Science. Outlines. Critical Practice Studies. 2003;5(1)

19. Andrade DR. Cultural Meaning Systems. In: Shweder R, Levine R, editors. Cultural Theory. Essays on Mind, Self, and Emotion. Sydney: Cambridge University Press. 1984.

20. Inkeles A, Levinson D. National Character: The study of Moda Personality and Sociocultural Systems. In: Lindzey C, Aronson E, editors. The Handbook of Social Psychology Vol IV. London: Massachusetts, Ontario, Addison-Wesley; 1969.

21. Lourié SV. Culture and its Script. An implicit generalized cultural script as an intracultural integrator. Sosial Sciences and Contemporary Word. $2017 ; 2$.

22. Markarian E. Capacity for World Strategic Management. Yerevan: Gitutun; 1998.
23. Markarian E. On primary methodological prerequisites of ethnic cultures research. Methodological problems of ethnic cultures. Erevan: izd-vo AN Arm.SSR; 1978.

24. Prangishvili A. Set as an intangible base of psychical reflection. In: Prangishvili AS, Sherozija AE, Bassina FV, editors. The unconscious. Nature, functions, methods of research. Tbilisi: Mecniereba; 1985.

25. Schwartz Th. The Structure of National Cultures. In: Funke P, editor Understanding of USA: A Cross-Cultural Perspective. Tubengen: Gunter Narr Verlal; 1989.

26. Schwartz Th. Where is the culture? In: Spindler G, editor. The Making of Psycholodgical Anthropology. Berkeley: University of California Press; 1978. 